and thus have an association with morbidity and mortality. Data regarding osteoporotic fractures are necessary in order to develop guidance and health policy in the region. SLE is an important risk factor for severe osteoporosis and must be kept in mind when developing guidance and health policy References:

[1] Jumei Xia, Ran Luo, Shuiming Guo, et al. Prevalence and Risk Factors of Reduced Bone Mineral Density in Systemic Lupus Erythematosus Patients: A Meta-Analysis. BioMed Research International. Volume 2019, Article ID 3731648, 10 pages.

[2] Irene E.M. Bultinka, Willem F. Lemsa. Lupus and fractures. Curr Opin Rheumatol 2016, 28:426-432.

Disclosure of Interests: Juan camilo Diaz-Coronado: None declared, Sebastian Herrera Speakers bureau: academic conference, Deicy Hernandez-Parra: None declared, Laura Betancur-Vasquez: None declared, Daniel Gonzalez-Hurtado: None declared, Juanita Gonzalez-Arango: None declared, laura Uribe-Arango: None declared, Maria Fernanda Saavedra Chacón: None declared, Jorge Lacouture-Fierro: None declared, Sebastian Guerra-Zarama: None declared, Santiago Monsalve: None declared, Jose David Serna Giraldo: None declared, Juan david Serna: None declared, Julian Barbosa: None declared, Ricardo Pineda.Tamayo: None declared

DOI: 10.1136/annrheumdis-2020-eular.6582

\section{SAT0464 MULTIPLE REBOUND-ASSOCIATED VERTEBRAL FRACTURES AFTER DENOSUMAB DISCONTINUATION IN RHEUMATOLOGY CLINIC}

G. Evangelatos ${ }^{1}$, G. E. Fragoulis ${ }^{2}$, A. Iliopoulos ${ }^{1} .{ }^{1} 417$ Army Share Fund Hospital (NIMTS), Rheumatology Department, Athens, Greece; ${ }^{2}$ National and Kapodistrian University of Athens, First Department of Propaedeutic Internal Medicine, Athens, Greece

Background: Denosumab, a monoclonal antibody against RANKL, is an effective treatment for osteoporosis. Discontinuation of denosumab has been shown to lead in multiple vertebral fractures in some patients due to a severe acceleration of bone resorption (rebound-associated vertebral fractures-RAVFs). Limited data published during the last 2 years highlighted this issue.

Objectives: The aim of this case series is to describe features of the denosumab-associated RAVFs and the characteristics of these patients.

Methods: Patients from our outpatient rheumatology clinic who were diagnosed with recent vertebral fractures after denosumab discontinuation from January 2019 to December 2019 were included. Diagnosis was based on $\mathrm{x}$-ray and/or magnetic resonance imaging (MRI) of thoracic $(T)$ or lumbar $(L)$ spine. All cases were the result of reduced compliance of the patients to the treatment regimen. A baseline x-ray examination was available in all patients included and was compared in order to exclude prevalent osteoporotic fractures. Demographic and clinical parameters were recorded.

Results: Nine patients ( 8 females) with a mean \pm SD age of $71.3 \pm 11.9$ years were included (Table 1). A total of 32 fractures occurred, affecting median 4 (range 1-6) vertebras (Figure 1). The mean $\pm S D$ duration of denosumab treatment prior to discontinuation was $54.0 \pm 30.1$ months, while the mean \pm SD time that RAVFs occurred after the last denosumab injection was $8.8 \pm 2.4$ (range 7-12) months. The most commonly affected vertebra was L3 (Table1). Most patients (66.7\%) did not have any prevalent osteoporotic fracture. Four patients $(44.4 \%)$ were receiving drugs that affected bone metabolism (mainly corticosteroids and aromatase inhibitors). Only $33.3 \%$ of the patients had a history of previous treatment with bisphosphonates.

Table 1. Characteristics of RAVFs and patients affected. L: Lumbar, T: Thoracic, SD: Standard Deviation

\begin{tabular}{lc}
\hline Females (\%) & $88.9 \%$ \\
Age (years) (mean \pm SD) & $71.3 \pm 11.9$ \\
Affected vertebras (median, range) & $4,1-6$ \\
Treatment duration (mean \pm SD) (months) & $54.0 \pm 30.1$ \\
Time after last injection (mean \pm SD) (months) & $8.8 \pm 2.4$ \\
Vertebral fracture site & 13 \\
T10 T11 T12 & 2 \\
L1 & 5 \\
L2 & 5 \\
L3 & 8 \\
L4 & 5 \\
L5 & 5 \\
Patients with prevalent osteoporotic fractures (\%) & 33.3 \\
Patients receiving drugs affecting bone metabolism (\%) & 44.4 \\
Patients with previous treatment with bisphosphonates (\%) & 33.3 \\
\hline
\end{tabular}

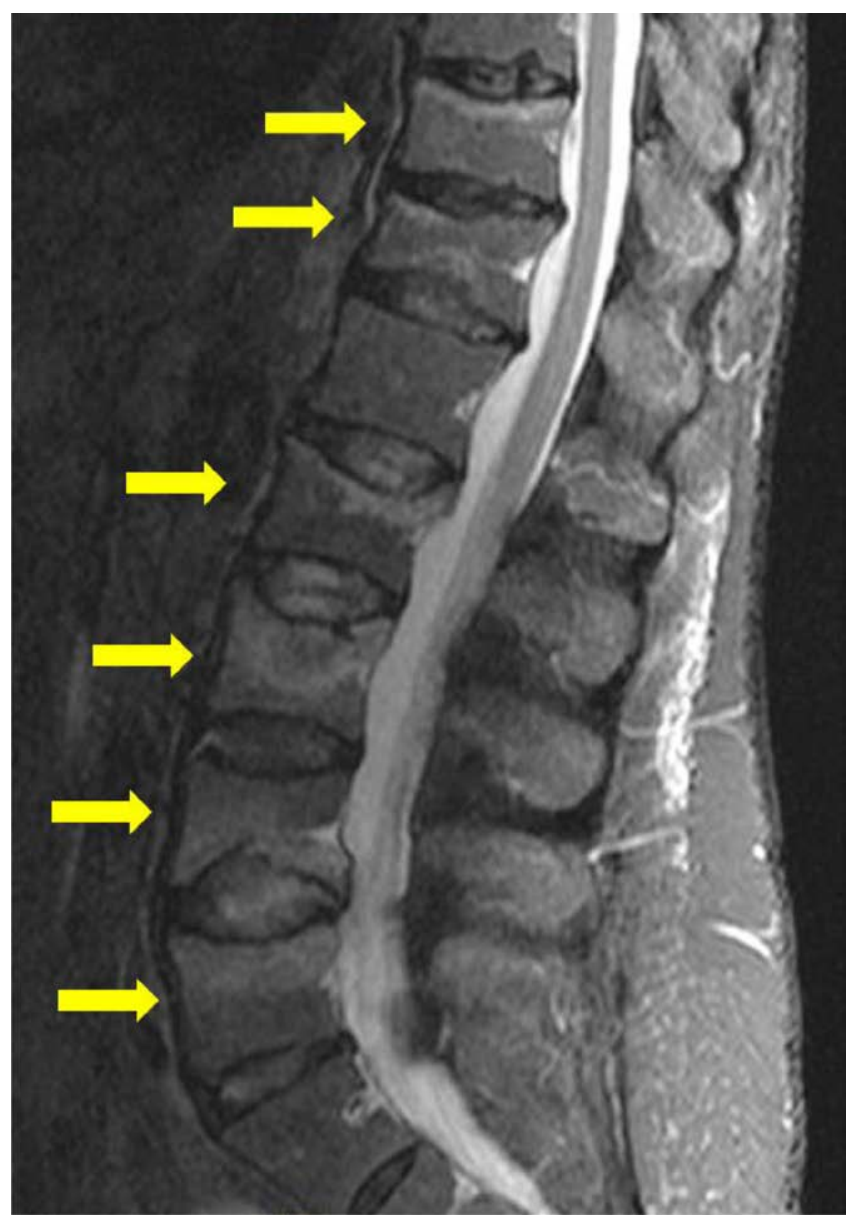

Figure 1. Multiple vertebral fractures (yellow arrows - T11, T12, L2-L5) in a patient 7.5 months after the last denosumab injection. T: thoracic, L: Lumbar

Conclusion: Denosumab-associated RAVFs usually occur within 7-12 months after the last denosumab injection and affect multiple vertebras. Most cases are associated with long-term ( $>2$ years) denosumab administration without previous treatment with bisphosphonates. Rheumatologists should be alert of this complication since the reported compliance in patients under denosumab treatment is only $46 \%$ (1) and the expected incidence of RAVFs after denosumab discontinuation has been reported to be $10 \%(2)$.

\section{References:}

[1] Durden E, Pinto L, Lopez-Gonzalez L, Juneau P, Barron R. Two-year persistence and compliance with osteoporosis therapies among postmenopausal women in a commercially insured population in the United States. Arch Osteoporos. 2017 Dec;12(1):22.

[2] McClung MR, Wagman RB, Miller PD, Wang A, Lewiecki EM. Observations following discontinuation of long-term denosumab therapy. Osteoporos Int 2017 May;28(5):1723-1732

Disclosure of Interests: None declared

DOI: 10.1136/annrheumdis-2020-eular.660

\section{SAT0465 $\quad$ FRACTURE RISK ASSESSMENT BY FRAX IN A SYSTEMIC LUPUS ERYTHEMATOSUS PORTUGUESE COHORT}

B. M. Fernandes ${ }^{1}$, S. Garcia ${ }^{1}$, S. Ganhão ${ }^{1}$, M. Rato ${ }^{1}$, F. Pinheiro ${ }^{1}$, M. Bernardes ${ }^{1}$, L. Costa ${ }^{1} .{ }^{1}$ Centro Hospitalar Universitário São João, Rheumatology, Porto, Portugal

Background: Osteoporosis is commonly seen in patients with Systemic Lupus Erythematosus (SLE), even in pre-menopausal patients. The etiology is multifactorial and chronic glucocorticoid therapy seems to play a central role. 